Igor Wysocki

ORCID: 0000-0002-4926-4010

Independent scholar

igorwysocki82@wp.pl

Dawid Megger

Uniwersytet Mikołaja Kopernika w Toruniu

dawid.megger95@gmail.com

\title{
Austrian welfare economics: A critical approach
}

Date of submission: 19.10.2018; date of acceptance: 28.02.2019

JEL Classification: B41, B53, D60, D63, P14

Keywords: welfare economics, Austrian school of economics, property rights, Rothbard, voluntary exchange, theory of threat

\begin{abstract}
Austrian welfare economics: A critical approach

It seemed that since Rothbard's (2008 [1956]) exquisite Toward a Reconstruction of Utility and Welfare Economics, one can make a case for the free market based on some modified concept of efficiency. Rothbard famously argued that being equipped with the notions of Pareto-superior moves and demonstrated preference suffices for the above purpose. Our agenda in the present paper is purely negative. First, we face the challenge - in our opinion, inadequately addressed in Austrian literature so far - of sharply defining Pareto-superior moves; to wit, how to evaluate whether a Pareto-superior move occurs; or, more specifically, what is the standard of comparison which would allow us to determine whether a given action constitutes a Pareto-superior move or not. Thus, we sieve out any approaches to social welfare that would be either trivial (and therefore uninteresting) and the ones that would be irreconcilable with fundamental Austrian premises (e.g., ordinal value scales and therefore non-aggregation of utility, etc.). As a result, we seemingly end up with what might constitute a specifically Austrian view on welfare, which non-surprisingly coincides with the actual positions taken by contemporary prominent Austrians themselves (for instance, see: Gordon, 1993; Herbener, 1997; Block 1995). Yet, the main thrust of our paper is to argue that this very position cannot withstand criticism, for it either makes an intuitively wrong prediction (as we demonstrate in our thought experiment) or it vitiates the argument for the free market from the concept of Pareto-efficiency.
\end{abstract}




\section{Introduction}

In this section, our aim is to seriously consider the question of the standard of comparison for Pareto-superior moves. In other words, what is this state of affairs (or action?) against which a given move is judged as Pareto-superior? By considering some reasonable alternatives, we shall charitably (but tentatively) argue for the seemingly only reasonable position, which, unsurprisingly, is the one adhered to by both Rothbard (2008 [1956]), Gordon (1993) and Herbener (1997), to name but a few.

First, let us consider why a Pareto-superior move cannot be conceived as the one which increases welfare as compared to the opportunity cost. At first glance, this position seems perfectly sound. It must be granted that there are no logical flaws therein but, alas, it is trivial. For it is true of all the actions conceivable that they increase welfare compared to their respective opportunity costs. After all, Austrians believe that people's actions demonstrate strict preference ${ }^{1}$ (or a weak preference for that matter - at least according to some of them, with one of the most adamant adherents of this view being Ben O'Neill [2010]), which in turn implies that having taken a given action the actor in question benefits at least ex ante, as compared to taking any other action or not taking any action at all. Hence, an actor, having acted in one way or the other, a fortiori benefits as compared to his opportunity cost, which is merely the second best opportunity foregone. Having said that, it must be noted that this understanding of the Pareto-superior move would prove too much. It not only argues for the free market but also for any other social arrangement as long as people act. Now, if literally all the actions are Pareto-efficient, there is no point in introducing the very predicate in question in the first place. It runs counter to the well-known principle in logic; to wit, that a predicate $\mathrm{P}$ is useless if there is no such thing that would instantiate non-P. Then $\mathrm{P}$ does not point to any distinctive feature of actions at all; it does not single out any subset of all the actions. In other words, $\mathrm{P}$ is utterly uninformative in the universe of actions.

To complete our reductio ad absurdum, let us demonstrate that the above understanding of Pareto-efficiency would be contrary to our well-established intuitions. Imagine a mugger coming to us and threatening with a "your money or your life" proposal. The analysis thereof employing the above-stated tentative concept of Pareto-superiority would have to run along, more or less, these lines. Once the mugger approaches us, he thereby demonstrates that he benefits compared to doing anything else, and therefore his welfare increases. What about us, the target of this proposal? By the same token, when we accede and some money changes hands in order to save our lives, we benefit since we demonstrate by the

${ }^{1}$ On the idea that choice always implies strict preference, see for instance: Block, 2009a, 2009b; Block and Barnett, 2010. 
very choice we make that we do prefer losing money to losing our lives. Hence, both parties benefit, which must mean that this "exchange" was Pareto-superior. If this conclusion is not plainly absurd, what is?

Another construal of a Pareto-superior move might be that the actor's welfare increases over time. It might be represented in a graph with the vertical axis denoting utility (here conceived of as the percentage share of the actor's satisfaction and the horizontal axis denoting ${ }^{2}$ ). If, over given time, the actions taken by the actor were to be conceived of as Pareto-superior moves, it might mean that the actor's welfare keeps increasing compared to all previous moments in time; that is to say, at any given moment in the scrutinized time-frame, the welfare is larger (in absolute terms) than in any other moment prior thereto. All the above-considerations might be put in the following graphic form:

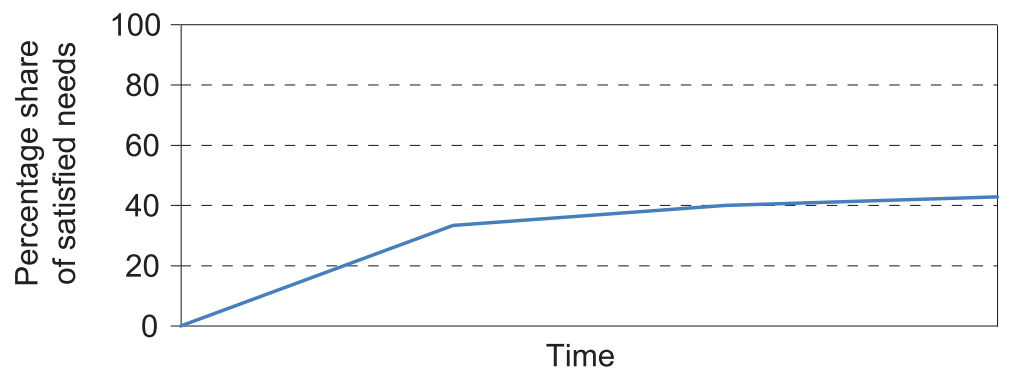

Figure 1. Utility as a function of time

Source: own work.

What is possibly wrong with this construal of Pareto-superiority from the distinctively Austrian position? Obviously, the apparently continuous line can be obviated by saying that it is a mere approximation of discreet utility increases, which is another way of stating the Austrian truth that utility might rise or drop, but there is no cardinal way of expressing this. In other words, utility can be arranged only ordinally (Rothbard, 2008 [1956], 232-243). However, there is a deeper problem with construing Pareto-superior moves as ordinally understood increases in utility. The problem with the above representation is that it erroneously a s sume s the stability of preferences over time. ${ }^{3}$ If this were indeed the case that a given actor cherishes the same preferences over time, and he successively satisfies them, it could coherently be maintained that his utility increases over time: he would be simply approximating $100 \%$ level of satisfaction. Yet, once we

2 The percentage share on the vertical axis is no necessity at all. Tentatively speaking, the vertical axis might represent cardinal utility or the ordinal one for that matter. The percentage share is designed to mean what share of needs of the actor in question are satisfied relative to all his needs (attended to or not). For the sake of argument, we assume that the higher percentage share of the actor's needs are attended to, the higher is his economic welfare. Given our percentage-share scale, we are not bothered in the least by the prediction that, ceteris paribus, the fewer needs the actor has, the higher his welfare is.

${ }^{3}$ On instability of preferences over time, see for example: Block and Barnett, 2012. 
introduce a bit of realism into the picture and admit that preferences change over time, there is simply no way of saying whether the actor is generally (relative to his maximum satisfaction, whatever that may be) more or less satisfied, since it is precisely this maximum satisfaction (our $100 \%$ point) that is a movable part of the whole picture. Concluding, given Austrian realist contention that preferences do change over time, it is impossible to interpret Pareto-superior moves as increases in utility over time (Rothbard 2008 [1956], 228-230).

Therefore, since the latter interpretation is incompatible with Austrianism and the former is simply trivial, we need to resort to a third option. What comes handy at this point is the original Rothbardian, (2008 [1956]) contention (also adhered to by Herbener $[1997,7])$ that it is only voluntary choices that constitute Pareto-superior moves. Rothbard does not address the compared-to-what issue, but we can make sense of his statement. What he most probably means is that an actual action taken by the actor raises his utility compared to the opportunity cost o n ly w it hin voluntary choices. The proviso of voluntariness seems indispensable, for it helps to obviate the triviality objection mentioned above. If the proviso were missing, it would only state the trivial truth that actual actions benefit the actor as compared to their respective opportunity costs. Rothbard's position, on the other hand, is much more informative and it predicts that a coerced choice does not constitute a Pareto-superior move, even though one still benefits by choosing what he chooses as compared to the opportunity cost. Fair enough, but what are the implications of that theoretical standpoint? Our argument is two-fold. First, we confront Rothbard's view with an original thought-experiment of ours showing that Rothbard would be committed to divergent judgments over utility increases (or decreases) even though the outcomes of two scenarios in our experiment as well as the actor's expected benefits are totally identical. Second, and more crucially, we claim that Rothbard's definition of Pareto-efficiency in terms of voluntariness vitiates the very argument for the free-market he tries to make. So, let us proceed and dismantle Rothbard on these two counts.

\section{Why Rothbard's argument for the free-market collapses}

Consider two proposals an economic actor can face:

1) Tax collector case: A tax collector comes to you and says: "Pay me $\$ 1,000$ or you will go to prison". You decide to succumb to his proposal. You pay and preserve the status quo.

2) Potential competitor case: You run a successful business and one day your potential competitor comes to you saying: "Pay me $\$ 1,000$ or I will open a competitive retail shop in close proximity to yours". You decide to accede to the person's proposal. You pay and preserve the status quo. 
Now, let us analyze the above scenarios from the angle of shared and distinctive properties. What immediately springs to mind is that the proposals differ in the alternatives to the options that the actor finally accedes to. These are, respectively, "or you will go to prison" and "or I will open a competitive retail shop in close proximity to yours". It is precisely the content of these parts of respective proposal that account for the difference in their legality. In a free society, Case 1 would be a case of extortion, since threatening somebody with imprisonment for nothing (after all, there would no positive duty to pay money to anybody in the absence of a contract between the parties in question) would be illegitimate; whereas Case 2 would be an instance of blackmail: threatening to open a competitive shop would be legal since the very action is legal — in the free market everybody enjoys a $1 \mathrm{ib}$ e r ty to start their own business enterprise. ${ }^{4}$ Therefore, if you do accede to proposal 1, the payment is involuntary; whereas in Case 2 the payment is voluntary.

On the other hand, let us describe the situation in non-normative terms. First and foremost, judging the exchange ex post, it is readily noticeable that the outcomes in the two cases are identical: the payment of the same amount was made merely to preserve the status quo. But what about ex ante analysis? In both scenarios, we would vastly prefer it if the persons coming up with the proposals "dropped dead"; and, more crucially, we also expect to benefit by paying as compared to the threatening alternatives (imprisonment or facing a new competitor). So, it seems reasonable to conclude that in terms of their economic efficiency, these two scenarios are indistinguishable. To reiterate, the same amount of money is paid to merely preserve the status quo. In ex ante sense, there is the same expectation that the payment of $\$ 1,000$ will improve the person's welfare relatively to either going to prison or facing a new competitor. ${ }^{5}$

Then, why should it matter at all for apparently value-free utility considerations whether the first proposal was illegal, while the other was legal? Yet, this is exactly what Rothbard's position predicts. Because the first proposal was coercive, the voluntariness condition was not met and the payment did not constitute a Pareto-superior move. The opposite applies to the second scenario: because the proposal was legal, the payment was voluntary. A voluntary choice is a sufficient condition for a Pareto-superior move to occur. So, quite unnaturally, Rothbard's approach predicts that even two identical outcomes (and ex ante expectations too!) can have two distinct underlying interpretations in terms of Pareto efficiency. The burden of proof seems to be on Rothbardian followers to account for this strange prediction.

Based on Herbener's (2008) and Wiśniewski's (2013) argument that we can infer stability of preference scales from the unchanging consequences of one's

\footnotetext{
${ }^{4}$ On the distinction between extortion and blackmail, see: Block, 2013.

5 Isn't Robert Nozick right in maintaining the distinction between productive and non-productive exchange (Nozick, 1999 [1974], 84-87)?
} 
past decisions, one can make a reservation that our Case 1 and Case 2 are misdescribed, and are thus fundamentally distinct. More specifically, it looks as if one can validly claim that the two scenarios adduced in our thought experiment do not control for voluntariness/involuntariness of one's choice, keeping everything else equal. For example, it might be objected that in Case 1, our economic actor (by acceding to the issued threat) does not get anything over and above what he has already had (money and liberty) and since he has not disposed of this certain amount of money so far just like that (that is in the absence of the threat in question), it can reasonably be inferred that the actor's welfare must have necessarily diminished. On the other hand, in Case 2, it seems that our actor buys something new: he pays one of his potential competitors to "drop dead"; that is, the former buys a more desirable business environment. At first glance, this rejoinder seems formidable but upon scrutiny, it misses the point. The problem with this objection is that it plays fast and loose with normalcy (with a normal or expected state of affairs serving as a benchmark for ordinal utility comparisons). That is, once we admit that in the event of not paying one's tax, one normally (or expectedly) goes to prison, we do benefit by acceding to a tax collector's threat simply as compared to a possible world in which we do not pay and we go to prison as a result. So, what the actor in Case 1 effectively buys is not going to prison - a more desirable social environment.

Secondly, even if we interpret the Rothbardian account of Pareto-superior moves as charitably as possible, it runs into insuperable logical problems when employed in his argument for the free market. It may be inferred from the above that the Rothbardian concept of Pareto-superior moves does not capture linguistic intuitions connected therewith. Linguistic intuitions aside, let us simply assume that Rothbard stipulates the concept of Pareto-superior moves and de fin e s ${ }^{6}$ them as increases in utility (compared to opportunity cost) within voluntary choices. But even this stipulative attempt fails when it tries to serve as a valuefree justification for the free market. It is because Rothbard (2008 [1956], 250) defines the free market as a collection of all voluntary exchanges. But now, if it is only within voluntary exchanges that Pareto-superior moves can materialize, then the whole argument is circular. To argue for the free market, we should have at our disposal a de scriptive (value-free) concept of efficiency and then argue for the free market on the basis that it happens to be the free market itself that maximizes efficiency. ${ }^{7}$ Instead, Rothbard assumes

${ }^{6}$ We do not take any stand on whether Rothbard ever did so explicitly or not. We are rather conducting some hermeneutic work on this outstanding essay "Toward a reconstruction of utility and Welfare Economics".

${ }^{7}$ At this point, it would be advisable to anticipate a possible rejoinder to our position that we violate Hume's ought-is principle and we try to move from facts to norms. Obviously, we do not make a case for the free-market based on efficiency alone. Of course, one normative premise would be missing. But the premise is rather uncontroversial: increasing efficiency, ceteris paribus, is good 
voluntariness as a necessary and sufficient condition for a Pareto-superior move. But then, if the concept of Par e to - su peri or move s relies on voluntariness, then the former cannot justify the free market, with the free market being defined as a universe of voluntary exchanges, since the Pareto-superior already a s s u m e s o 1 ly free-market transactions. In other words, the Rothbardian project is flawed as it begs the question.

\section{Conclusion}

In this short article we wanted to challenge the Rothbardian theory of welfare economics. As we think, we reasonably demonstrated that it suffers from some logical errors which we have presented above. In the first section we tried to show some possible ways of understanding the attempt of Austrian reconstruction of welfare economics in order to explicate how it should be properly construed. Showing that comparing Pareto-superior moves to opportunity cost yields trivialities and the concept of accumulation of utility is contrary to the assumptions of the Austrian method, we explained that the only rational position on this issue is to conceive of Pareto-superior moves in terms of both voluntariness and comparison to opportunity costs. Next, we presented two scenarios differing in terms of voluntariness/ involuntariness which ultimately bring about the same results. Therefore, we can justifiably ask what is in voluntariness that we should think makes exchange always effective? At the end, we noted that if we define Pareto-superior moves in terms of voluntariness and the free market as a system of exclu sively voluntary exchanges, the argument for the free market from the concept of thus conceived Pareto-superiority is an instance of circulus vitiosus.

\section{References}

Block, W. E. (1995). Ethics, efficiency, Coasean property rights and psychic income: A reply to Demsetz. Review of Austrian Economics, 8(2), 61-125.

Block, W. E. (2009a). Rejoinder to Machaj on indifference. New Perspectives on Political Economy, $5(1), 65-71$.

Block, W. E. (2009b). Rejoinder to Hoppe on indifference. The Quarterly Journal of Austrian Economics, 12(1), 52-59.

Block, W. E. (2013). Legalize Blackmail, New Orleans: Straylight Publishing, LLC.

(desired, welcome or whatever - to use some normatively charged language). So, to put it in a syllogistic form, our argument runs as follows:

1. Increasing efficiency is good (value-laden premise);

2. The free market happens to increase efficiency (empirical premise with a descriptive, valuefree notion of efficiency); and therefore:

Free markets are good. 
Block, W. E., Barnett, W. (2010). Rejoinder to Hoppe on indifference, once again. Reason Papers, 32, 141-154.

Block, W. E., Barnett, W. (2012). Transitivy and the Money Pump. The Quarterly Journal of Austrian Economics, 15(2), 237-251.

Gordon, D. (1993). Toward a deconstruction of utility and welfare economics. The Review of Austrian Economics, 6(2), 99-112.

Herbener, J. M. (1997). The Pareto rule and welfare economics. The Review of Austrian Economics, 10(1), 79-106.

Herbener, J. M. (2008). In defense of Rothbardian welfare economics. New Perspectives on Political Economy, 4(1), 53-78.

Nozick, R. (1999) [1974]. Anarchy, State, and Utopia. Oxford, UK, Cambridge, USA: Blackwell.

O'Neill, B. (2010). Choice and indifference: A critique of the strict preference approach. The Quarterly Journal of Austrian Economics, 13(1), 71-98.

Rothbard, M. N. (2008) [1956]. Toward a reconstruction of utility and welfare economics. In M. Sennholz (ed.), On Freedom and Free Enterprise: Essays in Honor of Ludwig von Mises (224-262). Auburn: The Ludwig von Mises Institute.

Wiśniewski, J. B. (2013). Non-excludability, externalities, and entrepreneurship: An overview of the Austrian theory of common goods. Journal of Prices \& Markets, 1(1), 57-68. 